\title{
Editorial
}

\section{Nutritional environments affecting the future of our children}

Children today are exhibiting chronic conditions that used to be seen only in adults. While the developing study of epigenetics draws our attention to intra-uterine and neonatal phases of life as predictors of health outcomes later in the life course ${ }^{(1,2)}$, lifestyle still greatly affects the phenotypic manifestations of our genetic heritage. In other words, it pays to watch what we eat and how we spend our time. The findings that the perinatal nutritional environment may affect food preference later in life, and that the first months and years of life are so critical to survival, health and achievement, also suggest that efforts to support and educate women of childbearing age are justified, and that we should increase our efforts to advocate for food security - access to adequate nutrition, safe drinking water and health-care services - for all.

The simultaneous health hazards of under- and overweight occurring in countries experiencing nutritional transition exemplifies the current problem of unsustainable food consumption and production patterns. In this issue we highlight five studies that focus on this topic: one from Colombia $^{(3)}$, two from Kenya ${ }^{(4,5)}$ and two from Brazil ${ }^{(6,7)}$.

Sarmiento et $a l^{(3)}$ point out the double burden of underweight in adolescent pregnant women and overweight in adult pregnant women in Colombia, a country experiencing nutritional transition. Thirty-one per cent of pregnant adolescents ( $n$ 430) were underweight for gestational age, compared with $14.5 \%$ of the adult women ( $n$ 1272). On the other hand, the prevalence of overweight in adolescents (18\%) was only half that in adult women (37\%). Higher wealth index was associated with less underweight. These findings point to the need for different approaches for the different age groups.

As de Carvalho Cremm et al. ${ }^{(6)}$ report in this issue, the nutritional status of 531 urban Brazilian children under 10 years of age was assessed in interviews with their mothers. The lower the socio-economic status of the family, the higher was the likelihood of the children being overweight. The high prevalence of overweight (36.9\%) was alarming, being higher than observed in developed countries or in previous studies in Brazil. There was an association between active transportation (walking or cycling) and less overweight only among children younger than 6 years. Encouraging children to be active from an early age and maintaining this through adolescence to adulthood could prove to be helpful in avoiding overweight. The Brazilian findings show the need for health-promoting urban design.

The other Brazilian study in this issue, by Fernandes et $a l^{(7)}$, reports on a cohort of undernourished children ( $n$ 228) from the southern slums of Sao Paulo who had received treatment at the Centre of Nutritional Recovery and Education under a day-hospital regime between the years 1994 and 2009. Their findings revealed that children without neuropsychomotor developmental delay who were admitted after 24 months of age were less likely to be rehabilitated than others treated at a younger age.

In Kenya, as in other East African nations, the diets in poor communities are largely plant-based and intake of animal foods, such as meat and milk, is limited. The relatively low energy density of such diets makes it difficult for young children to consume sufficient energy. In this issue Long et al. ${ }^{(5)}$ report on their 5-month feeding intervention comparing the effects of adding animal foods (milk and meat) to plant foods (millet) on child growth in rural Kenya. The sample consisted of 303 children aged 11-40 months randomised to three groups: plain millet porridge, porridge with milk or porridge with beef. The addition of meat or milk to the porridge did not increase growth rate compared with the plain millet porridge, but this needs to be confirmed in a narrower age range. These findings are important, particularly in a sample in which $26 \%$ of children showed stunted growth, a sign of long-term nutritional deficiency that, if not corrected, is associated with cognitive, motor and behavioural deficits.

The other study from Kenya in this issue, by Gewa and Yandell ${ }^{(4)}$, provides details of the sad nutritional state there. In a sample of 3793 children under 5 years of age, $37 \%$ were stunted (30\% of the 1851 children between the ages of 0 and 24 months; $40 \%$ of the 1942 children aged 25-59 months). The authors point out that in comparison with results from a similar study in Kenya a decade ago, underweight had decreased from $27 \%$ to $13-17 \%$ while the prevalence of wasting had not changed (4-8\%). Analysis of contributory factors demonstrated that for the older children, the more distal maternal and household factors (such as household wealth and mother's educational level) had a stronger impact on child undernutrition, whereas the more proximal factors (all child-related factors, poor maternal nutritional status and age at first birth) had the strongest impact on younger children. This study shows how a deficient environment may be associated with current and ongoing exposure to nutritional deficiencies, resulting in inadequate gains in stature and body weight, both for the mother and the child.

While the issues at hand in the developing world are more pressing and alarming, other articles highlighted in this issue focus on the nutritional well-being of children in developed countries. Huybrechts et al. ${ }^{(8)}$ investigated intakes and dietary sources of $\mathrm{Na}$ and $\mathrm{K}$ among $2 \cdot 5-6 \cdot 5$-year-old 
Flemish children ( $n$ 696). Their results show that as the main dietary sources of $\mathrm{Na}$ and $\mathrm{K}$ are clearly different, it would be possible to decrease intake of the former without negatively affecting the latter. Although we know that high consumption of salt is associated with elevated blood pressure, we have not succeeded in sufficiently reducing its intake in children, our most vulnerable in this case. Higher intakes of $\mathrm{K}$, on the other hand, could have a positive effect, lowering blood pressure. Among the pre-school children in Huybrechts et al.'s study, the main K sources included sugared milk drinks, fried potatoes, milk and fruit juices, whereas fruit and vegetables might be considered a better choice. If salt content in bread, soup, cold meat cuts and other meat products contributing to $\mathrm{Na}$ intake among children could be reduced, and the consumption of fruit and vegetables increased, we could go a long way toward preventing CVD and kidney damage in children. Huybrechts et al.'s paper is a call to the food industry to change the nutritional environment for the better by making changes to the products it offers.

But how do we get children to eat more fruit and vegetables? In this issue, Melbye et al. ${ }^{(9)}$ report from crosssectional surveys among pre-adolescent children ( $n$ 796) and their parents $(n$ 963) in Norway. Child cognition (attitudes, social influence, self-efficacy) explained 29\% of the variance in child's intention to eat fruit and $25 \%$ of actual fruit consumption, and $42 \%$ of the variance in intention to eat vegetables and $27 \%$ of actual consumption. Parent-reported feeding practices added very little (3-4\%) to the explanatory power, but parents did influence the child food environment by having vegetables available. These findings are a reminder of the continued need for education to change attitudes, knowledge and skills among children and parents to improve dietary intake.

In childhood, but also throughout the life course, we are at the mercy of those who care for us, be it our parents, family, community or society. Our health and well-being is dependent on the decision making of others shaping our environment. While Home Economics/Family and Consumer Science focuses on family decision making regarding resource management, Public Health Nutrition should focus on steering that decision making with research evidence and through advocating for environments that are supportive of sustainable nutritional well-being and food security for all.

Also in this issue we include the speech made by Professor Antonia Trichopoulou ${ }^{(10)}$ when she received the Federation of European Nutrition Societies award in October 2011. This discusses the fate and value of traditional foods and sustainable diets, referring to the impact on both the health of the consumer and of the environment, across the globe. In the face of globalization these are both in danger of being lost.

\section{Irja Haapala \\ Allison Hodge \\ Marilyn Tseng \\ Geraldine McNeill \\ Deputy Editors}

Agneta Yngve

Editor-in-Chief

\section{References}

1. Berni Canani R, Di Costanzo M \& Leone L (2011) Epigenetic mechanisms elicited by nutrition in early life. Nutr Res Rev 24, 198-205.

2. Park LK, Friso S \& Choi SW (2012) Vitamins, infectious and chronic disease during adulthood and aging. Nutritional influences on epigenetics and age-related disease. Proc Nutr Soc 71, 75-83.

3. Sarmiento OL, Ramirez A, Kutschbach BS et al. (2012) Nutrition in Colombian pregnant women. Public Health Nutr 15, 955-963.

4. Gewa CA \& Yandell N (2012) Undernutrition among Kenyan children: contribution of child, maternal and household factors. Public Health Nutr 15, 1029-1038.

5. Long JK, Murphy SP, Weiss RE et al. (2012) Meat and milk intakes and toddler growth: a comparison feeding intervention of animal-source foods in rural Kenya. Public Health Nutr 15, 1100-1107.

6. de Carvalho Cremm E, Marrocos Leite FH, de Abreu DSC et al. (2012) Factors associated with overweight in children living in the neighbourhoods of an urban area of Brazil. Public Health Nutr 15, 1056-1064.

7. Fernandes MBF, López RVM, de Albuquerque MP et al. (2012) A 15-year study on the treatment of undernourished children at a nutrition rehabilitation centre (CREN), Brazil. Public Health Nutr 15, 1108-1116.

8. Huybrechts I, De Keyzer W, Lin Y et al. (2012) Food sources and correlates of sodium and potassium intakes in Flemish pre-school children. Public Health Nutr 15, 1039-1046.

9. Melbye EL, Øverby NC \& Øgaard T (2012) Child consumption of fruit and vegetables: the roles of child cognitions and parental feeding practices. Public Health Nutr 15, 1047-1055.

10. Trichopoulou A (2008) Diversity vs. Globalization: traditional foods at the epicenter. Public Health Nutr 15, 951-954. 